\title{
Reliability-Based Optimization of the Coupled Structural-Acoustic System with Random Parameters
}

\author{
Xiaojun Wang, Yunlong Li, Zhiliang Ma and Zhiping Qiu \\ Institute of Solid Mechanics, Beihang University, Beijing,100191, China
}

\begin{abstract}
(Received 18 February 2014; accepted: 19 April 2016)
Structural noise is an important factor that endangers aircraft fatigue life and flight safety. It also has a negative effect on aircraft stealth performance and noise navigability. An optimal design of a structure-acoustic coupled system is an effective way to reduce noise and vibration. Due to the uncertainties that exist in the structural and acoustical parameters, the traditional deterministic optimization method may be unfeasible when the parameters are subject to fluctuations. This means that when the parameters are uncertain, the results obtained from the deterministic optimization method may be beyond their constraints. This paper proposes to apply the stochastic reliability-based optimization method to the design optimization of the coupled structural-acoustic system with random parameters. A comparison between the results of the stochastic reliability-based method, the safety factorbased method, and the deterministic method show that the first two methods can effectively consider the dispersion of the parameters.
\end{abstract}

\section{INTRODUCTION}

Due to the modern industry's rapid development, traffic, city construction, and noise pollution have all attracted attention because they are harmful to structural performance and the general populace's health. Aircraft noise affects both the comfort and work efficacy of the pilot as well as the normal use of instruments inside the aircraft. Uncertainty widely exists in the objective world: it is inevitably subjected to the impact of the uncertainty of a load, structural size, material properties, the influence of various sudden external factors in production, design and use of aircrafts, spacecrafts, etc. These will all have an effect on the working characteristics and normal use of structures and could even lead to failure.

Since the 1970's, some scholars have begun to pay close attention to uncertain structure vibrations and acoustic radiation and have obtained some research results. Shuku and Ishihara ${ }^{1}$ investigated the analysis of the acoustic field in irregularlyshaped rooms using the finite element method. Craggs ${ }^{2}$ proposed an acoustic finite element approach for studying boundary flexibility and sound transmission between irregular enclosures. Chen and Chertock ${ }^{3,4}$ computed sound radiation by using the boundary element method. Marburg 5 studied an optimization problem of the acoustic radiation of finite element beam structures, and analyzed the influence of variables on the objective function where the variables were density, thickness, and young's modulus. Bös ${ }^{6}$ studied the optimization problem of three-dimensional structural acoustic performance. Mullen and Muhanna ${ }^{7}$ considered the static structure problem with uncertain structural loads based on the fuzzy set theory and interval analysis. Zheng-Dong $\mathrm{Ma}^{8-11}$ studied the sensitivity of response sound pressure, eigenvalue, and eigenvector to structural parameters based on the modal method, the iterative method, and the direct method. Papadopoulos ${ }^{12}$ constructed a finite element model of a room sound field and improved the sound quality of a room by redistributing the low frequency sound modal. Denli ${ }^{13}$ studied the structural vibration and acoustic radiation optimization by optimizing the boundary condition. Christensen ${ }^{14,15}$ studied the coupled structuralacoustic sensitivity analysis and optimization problem.

The Stochastic reliability-based optimization method is a rather classical approach in the field of optimization, but it has never been used for acoustic optimization. Besides, the previous optimization of the coupled structural-acoustic system were still limited to the deterministic method, and did not take the system parameter uncertainties into account. Deterministic structural optimization design often fails to consider the influence on structural performance by the randomness of material parameters, geometric dimensions, and loading. The optimal solution is usually located at the boundary of the constraint condition because if the randomness of the parameters is considered, the optimal solution may be in violation of the constraint condition and lead to an optimization failure.

The contribution of this paper is to overcome the shortcomings of the structural-acoustic deterministic optimization method by using two different methods: the interference theory of stress- intensity ${ }^{16-18}$ and the stochastic reliability-based optimization method, which are both applied to the coupled structural-acoustic system with established random parameters.

\section{THE FINITE ELEMENT METHOD OF COU- PLED STRUCTURAL-ACOUSTICSYSTEM}

\subsection{The Finite Element Equation of the Cou- pled Structural-Acoustic System}

The finite element equation of the coupled structuralacoustic system under frequency domain is as follows:

$$
-\omega^{2} \mathbf{M U}+j \omega \mathbf{C U}+\mathbf{K U}=\mathbf{F}
$$


where $\mathbf{M}=\left[\begin{array}{cc}\mathbf{M}^{s} & \mathbf{0} \\ \mathbf{M}^{\text {couple }} & \mathbf{M}^{a}\end{array}\right] ; \mathbf{C}=\left[\begin{array}{cc}\mathbf{C}^{s} & \mathbf{0} \\ \mathbf{0} & \mathbf{C}^{a}\end{array}\right] ; \mathbf{K}=$ $\left[\begin{array}{cc}\mathbf{K}^{s} & \mathbf{K}^{\text {couple }} \\ \mathbf{0} & \mathbf{K}^{a}\end{array}\right] ; \mathbf{U}=\left\{\begin{array}{c}\mathbf{U}^{s} \\ \mathbf{P}\end{array}\right\} ; \mathbf{F}=\left\{\begin{array}{c}\mathbf{F}^{s} \\ 0\end{array}\right\} ; \mathbf{M}^{\text {couple }}=$ $-\left(\mathbf{K}^{\text {couple }}\right)=\mathbf{S}^{T}$.

$\mathbf{M}^{\text {couple }}$ and $\mathbf{K}^{\text {couple }}$ represent the coupled stiffness matrix and coupled mass matrix, respectively; $\mathbf{K}^{s}$ and $\mathbf{K}^{a}$ represent the total stiffness matrix of structure and sound field, respectively; $\mathbf{M}^{s}$ and $\mathbf{M}^{a}$ represent the total mass matrix of structure and sound field, respectively; $\mathbf{F}^{s}$ is the external forces vector applied to the structure; $\mathbf{U}^{s}$ is the node displacement amplitude vector of the structure; $\omega$ is the excitation natural frequency; $\mathbf{C}^{s}$ and $\mathbf{C}^{a}$ represent the damping matrix of structure and sound field respectively; $\mathbf{P}$ is the unknown sound pressure.

\subsection{The Finite Element Method for Fre- quency Response Analysis for the Cou- pled Structural-Acoustic System with Random Parameters}

A parameter vector $\boldsymbol{\alpha}=\left(a_{1}, a_{2}, \ldots a_{m}\right)^{T}$ is used to denote all the physical parameters of the structural-acoustic system, $m$ is the structural parameter number. The matrix and vector of the coupling finite element equation could be expressed as the function of the parameter vector $\boldsymbol{\alpha}$. Thus, Eq. (1) can be represented in the following form:

$$
-\omega^{2} \mathbf{M}(\boldsymbol{\alpha}) \mathbf{U}(\boldsymbol{\alpha})+j \omega \mathbf{C}(\boldsymbol{\alpha}) \mathbf{U}(\boldsymbol{\alpha})+\mathbf{K}(\boldsymbol{\alpha}) \mathbf{U}(\boldsymbol{\alpha})=\mathbf{F}(\boldsymbol{\alpha}) .
$$

It is assumed that the uncertain parameter vector has a normal distribution and the random variables are independent of each other, namely:

$$
\boldsymbol{\alpha} \sim N\left(\boldsymbol{\alpha}^{c}, \boldsymbol{\sigma}_{a}\right)
$$

The solution to the coupled structural-acoustic system with random parameters is converted to find all of the solutions that satisfy Eq. (2), namely:

$$
\begin{array}{r}
\boldsymbol{\Omega}=\left\{\mathbf{U}(\boldsymbol{\alpha}) \mid-\omega^{2} \mathbf{M}(\boldsymbol{\alpha}) \mathbf{U}(\boldsymbol{\alpha})+j \omega \mathbf{C}(\boldsymbol{\alpha}) \mathbf{U}(\boldsymbol{\alpha})\right. \\
+\mathbf{K}(\boldsymbol{\alpha}) \mathbf{U}(\boldsymbol{\alpha})=\mathbf{F}(\boldsymbol{\alpha})\} .
\end{array}
$$

\section{STOCHASTIC RELIABILITY-BASED OPTIMIZATION METHOD}

\subsection{Model of Stochastic Reliability-Based Optimization}

A class of important problems in structural stochastic reliability-based optimization design minimizes the structural weight by selecting a reasonable distribution of the structural section size in a given reliability. Obviously, this kind of structural design is economical and reliable. Usually, structural weight is expressed as a linear function of the component's cross section dimensions (the design variables). One model of the stochastic reliability-based optimization is as follows:

$$
\left\{\begin{array}{l}
\text { Find } \mathbf{x}\left(x_{1}, x_{2}, \ldots, x_{n} \in R^{n}\right) \\
\min W(\mathbf{x})=\sum_{j=1}^{n} w_{j}\left(x_{j}\right) \\
\text { s.t. } g(\mathbf{x})=\beta_{s}(\mathbf{x})-\beta_{s}^{\alpha} \geq 0 \\
\mathbf{x}^{l} \leq \mathbf{x} \leq \mathbf{x}^{u}
\end{array} ;\right.
$$

Among them, $\mathbf{x}$ is the design variable of the structure; $W$ is the mass of the structure; $\beta_{s}$ is the index reliability of a constraint; $\beta_{s}^{\alpha}$ is the lower limit value of the reliability constraints.

\subsection{The Mean Value First Order and Second Moment (MVFOSM) Reliability Method}

The basic idea of the MVFOSM reliability method is to expand the nonlinear limit state functions at midpoints of random variables, ignore the higher order terms rather than second order, and then approximately calculate the mean and standard deviation of the limit state functions. The reliability index can be expressed as functions of the mean and standard deviation.

In stochastic reliability-based optimization of the coupled structural-acoustic system with random parameters, if the response $\mathbf{U}(\boldsymbol{\alpha}, \omega)$ satisfies the constraint that has a normal distribution $\mathbf{U}_{\delta} \sim N\left(\mu_{\delta}, \sigma_{\delta}\right)$, the limit state functions about the response amplitude and the constraint can be represented as:

$$
\mathbf{Z}=\mathbf{U}_{\delta}-\mathbf{U}(\boldsymbol{\alpha}, \omega)
$$

A Taylor series expansion about the limit state functions Eq. (6) at the midpoints of uncertain parameters $\boldsymbol{\alpha}^{c}$ is then implemented:

$$
\begin{aligned}
\mathbf{Z}=\mathbf{U}_{\delta} & -\mathbf{U}\left(\boldsymbol{\alpha}^{c}, \omega\right)+\sum_{i=1}^{m} \frac{\partial \mathbf{U}\left(\boldsymbol{\alpha}^{c}, \omega\right)}{\partial \alpha_{i}} \delta \alpha_{i} \\
& +\sum_{i, j=1}^{m} \frac{\partial \mathbf{U}^{2}\left(\boldsymbol{\alpha}^{c}, \omega\right)}{\partial \alpha_{i} \partial \alpha_{j}} \delta \alpha_{i} \delta \alpha_{j}+\cdots
\end{aligned}
$$

According to the MVFOSM reliability method, the mean $\mu_{z}$ and the variance $\sigma_{z}^{2}$ of the limit state functions are expressed as follows:

$$
\begin{gathered}
\boldsymbol{\mu}_{\mathbf{z}}=\boldsymbol{\mu}_{\boldsymbol{\delta}}-\mathbf{U}\left(\boldsymbol{\alpha}^{c}, \omega\right)+\sum_{i=1}^{m} \frac{\partial \mathbf{U}\left(\boldsymbol{\alpha}^{c}, \omega\right)}{\partial \alpha_{i}} \delta \alpha_{i} \\
\boldsymbol{\sigma}_{\mathbf{z}}^{2}=\boldsymbol{\sigma}_{\boldsymbol{\delta}}^{2}+\sum_{i=1}^{m}\left[\frac{\partial \mathbf{U}\left(\boldsymbol{\alpha}^{c}, \omega\right)}{\partial \alpha_{i}}\right]_{\mu_{\alpha^{c}}}^{2} \sigma_{\alpha_{i}}^{2}
\end{gathered}
$$

The central difference method is applied to approximate the derivative of the above matrices or vectors about $\alpha$ :

$$
\begin{gathered}
\frac{\partial \mathbf{U}\left(\boldsymbol{\alpha}^{c}, \omega\right)}{\partial \boldsymbol{\alpha}} \approx \frac{\mathbf{U}\left(\boldsymbol{\alpha}^{c}+\delta \boldsymbol{\alpha}, \omega\right)-\mathbf{U}\left(\boldsymbol{\alpha}^{c}-\delta \boldsymbol{\alpha}, \omega\right)}{2 \delta \boldsymbol{\alpha}} \\
\delta \boldsymbol{\alpha}=\boldsymbol{\alpha}-\boldsymbol{\alpha}^{c}
\end{gathered}
$$

By substituting Eqs. (10) and (11) into Eqs. (8) and (9), the mean and variance of the limit state functions can be obtained.

The reliability index $\boldsymbol{\beta}$ and failure probability $\mathbf{P}_{f}$ can be evaluated using Eqs. (12) and (13):

$$
\begin{gathered}
\boldsymbol{\beta}=\frac{\boldsymbol{\mu}_{\mathrm{z}}}{\boldsymbol{\sigma}_{\mathrm{z}}} ; \\
\mathbf{P}_{\mathbf{f}}=\Phi(-\boldsymbol{\beta}) .
\end{gathered}
$$




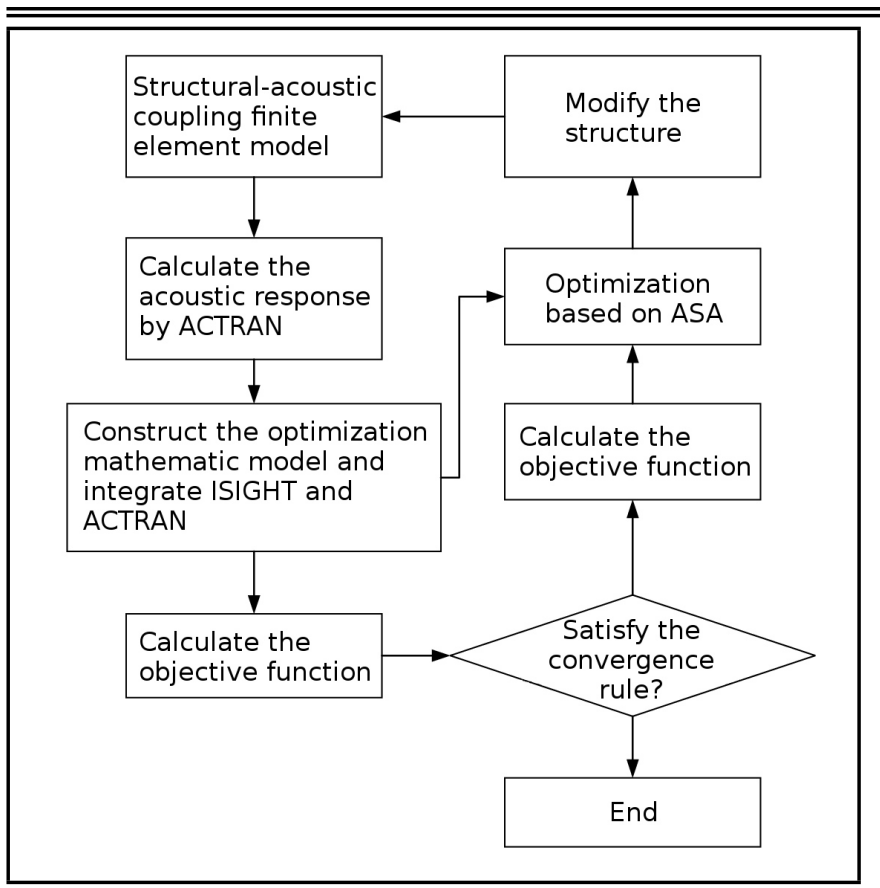

Figure 1. The flow chart of integration optimization for both ISIGHT and ACTRAN.

\section{SAFETY FACTOR METHOD BASED ON RELIABILITY}

In conventional mechanical design, strength calculation is carried out according to the principle of $s \leq r / n$, where $s$ is the load stress, $r$ is material strength, and $n$ is the safety factor. The safety factor includes uncertain factors such as the difference in calculation methods, the manufacturing allowable deviation, and the difference between actual stress and theoretical stress. As a result, conventional mechanical design is bound to result in a lot of unreasonable designs. The main reason is that $s \leq r / n$ can't reflect the changing law of stress and strength. In fact, even though the component is made from the same material and subjected to the same loading, if the changing law of strength and load is different, the failure probability may be different. In short, conventional design doesn't consider the consequences of failure.

Due to all of these reasons and the lack of any suitable theories or sufficient experimental data, our country's current given safety factor in the specifications and standards are usually too conservative. It may not be economical and may even cause the design to be unreliable. Therefore, in recent years, people have associated the safety factor with stress and strength, and have put it forward based on reliability so it can improve the design's reliability.

The mean safety factor is defined as the ratio of the mean of parts intensity to stress in the dangerous section parts:

$$
n=\frac{\mu_{\delta}}{\mu_{s}}
$$

When the stress and intensity obey normal distribution, the mean safety factor is associated with the reliability of the parts, so we have the equation:

$$
\beta=\frac{\mu_{\delta}-\mu_{s}}{\sqrt{\sigma_{\delta}^{2}+\sigma_{s}^{2}}}
$$

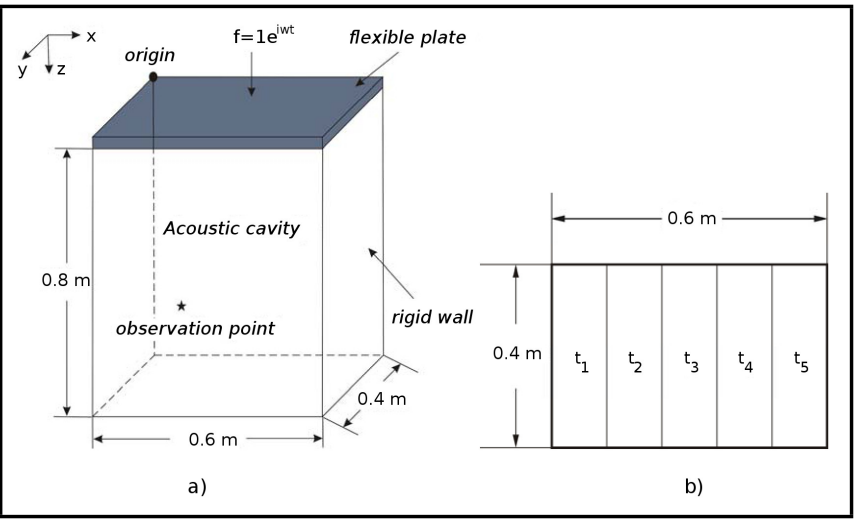

Figure 2. The coupled structural-acoustic system: a) a cuboid cavity and b) the distribution of design variables about plate thickness.

$\beta$ is the reliability index. According to Eqs. (14) and (15), the mean safety factor $n$ can be rewritten as:

$$
n=\frac{\mu_{\delta}}{\mu_{\delta}-\beta \sqrt{\sigma_{\delta}^{2}+\sigma_{s}^{2}}} .
$$

This paper introduces the stress-intensity interference theory to the coupled structural-acoustic system. When a stochastic reliability-based optimization of the structural-acoustic system is implemented, we make the value of the mean and variance of the acoustic response and its constraints correspond to the mean and variance of stress and strength in Eq. (16), respectively. We can obtain the safety factor corresponding to each iterative step of stochastic reliability-based optimization (as can be seen from Fig. 3c). If we implement the safety factor based optimization, we should choose the maximum safety factor obtained from stochastic reliability- based optimization as the safety factor.

\section{THE IMPLEMENTATION METHOD OF THE STRUCTURAL-ACOUSTIC OPTIMIZATION}

TThe structural-acoustic finite model and the optimization mathematic model should be established before optimization. And the proper mathematical method should be selected to implement the optimization. In the process of acoustic optimization, each iteration process needs to compute the acoustic response of the system. In this paper, the acoustic responses are obtained by ACTRAN software. The optimization processes are based on the integration of ACTRAN and ISIGHT. Response values calculated by ACTRAN can be transformed into the objective function value through multidisciplinary design language within the ISIGHT. The adaptive simulated annealing algorithm (ASA) is used to find the optimization solution. The integrated block diagram is shown in Fig. 1. ASA is a variant of the simulated annealing (SA) algorithm in which the algorithm parameters that control temperature schedule and random step selection are automatically adjusted according to algorithm progress. This makes the algorithm more efficient and less sensitive to user defined parameters than canonical SA. These are in the standard variant often selected on the basis of experience and experimentation (since optimal values are problem dependent), which represents a significant deficiency in practice. Certainly, the optimization procedure based on deterministic analysis is also able to reduce the value of acoustic responses of structures ${ }^{19-22}$ significantly. 


\section{NUMERICAL EXAMPLE}

A 3D acoustic cuboid model with length $(0.6 \mathrm{~m})$, width $(0.4 \mathrm{~m})$ and height $(0.8 \mathrm{~m})$ is shown in Fig. 2a. A flexible aluminum plate with the thickness of $6 \mathrm{~mm}$ is imposed on one surface of the cuboid cavity $z=0$, which composes a coupled structural-acoustic system. The remaining surfaces are perfectly rigid and the outer environment is a vacuum. The density, elastic modulus, damping coefficient, and Poisson ratio of the aluminum plate are $2700 \mathrm{~kg} \cdot \mathrm{m}^{-3}, 70 \mathrm{GPa}, 0.01$, and 0.3 , respectively. The cuboid cavity is surrounded by air with density $1.225 \mathrm{~kg} \cdot \mathrm{m}^{-3}$ and sound speed $340 \mathrm{~m} \cdot \mathrm{s}^{-1}$.

A harmonic excitation with the amplitude of $1 \mathrm{~N}$ is imposed at the central point of the flexible plate along the vertical direction. The frequency step is selected as $2 \mathrm{~Hz}$ to analyze the deterministic coupled system in the frequency domain of 1$300 \mathrm{~Hz}$. From the results on field point $0.1,0.1$, and 0.6, we know that the first two characteristic frequencies are located in the values of $108 \mathrm{~Hz}$ and $214 \mathrm{~Hz}$, respectively. Here, we select the thicknesses of the sub-block regions in the aluminum plate as design variables $\mathbf{t}=\left(t_{1}, \cdots, t_{5}\right)^{T}$ as shown in Fig. 2. Supposing that the mean square sound pressure amplitude at ten special frequencies, such as $104 \mathrm{~Hz}, 106 \mathrm{~Hz}, 108 \mathrm{~Hz}, 110 \mathrm{~Hz}$, $112 \mathrm{~Hz}, 210 \mathrm{~Hz}, 212 \mathrm{~Hz}, 214 \mathrm{~Hz}, 216 \mathrm{~Hz}$, and $218 \mathrm{~Hz}, M S P_{10}$ is less than $40 \mathrm{~Pa}$ (Stochastic reliability-based optimization requires its reliability not less than 0.99 ). The objective function is to find the optimal solution to make the total mass as small as possible. The initial value of the design variable is $0.006 \mathrm{~m}$, with a range of $0.003 \mathrm{~m}$ to $0.007 \mathrm{~m}$. All of the random variables have a normal distribution and are independent of each other. The stochastic reliability- based optimization design and safety factor-based optimization design (with the aid of ACTRAN and ISIGHT software) when the variation coefficient of random variables is $0.02,0.05$, and 0.1 respectively, was implemented.

\subsection{Deterministic Optimization of the Structural-Acoustic System}

The mathematical model of deterministic optimization about this example is:

$$
\left\{\begin{array}{l}
\min W \\
\text { s.t. } M S P_{10} \leq 40 \mathrm{~Pa} \\
3 \mathrm{~mm} \leq t_{1}, t_{2}, t_{3}, t_{4}, t_{5} \leq 7 \mathrm{~mm}
\end{array} ;\right.
$$

The deterministic optimization results are show in Table 1 to Table 3.

\subsection{Optimization When the Variation Coeffi- cient of Random Variables Is $\mathbf{0 . 0 2}$}

1) The stochastic reliability-based optimization method

The mathematical model of stochastic reliability-based optimization in this example is:

$$
\left\{\begin{array}{l}
\min W \\
\text { s.t. } \beta \geq 2.3263^{*} \\
3 \mathrm{~mm} \leq \mathbf{t}_{\mathbf{1}}, \mathbf{t}_{\mathbf{2}}, \mathbf{t}_{\mathbf{3}}, \mathbf{t}_{\mathbf{4}}, \mathbf{t}_{\mathbf{5}} \leq 7 \mathrm{~mm}
\end{array}\right.
$$

*(corresponding to the reliability not less than 0.99 );

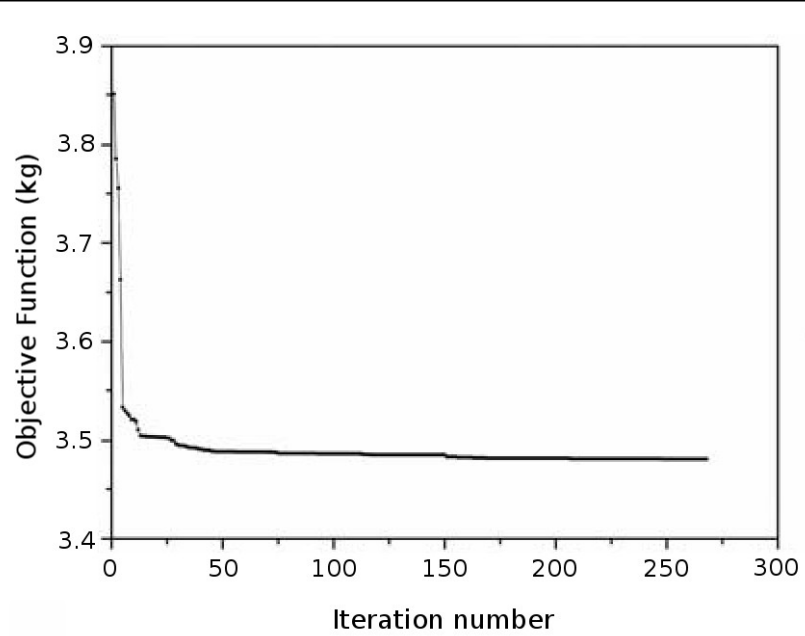

a)

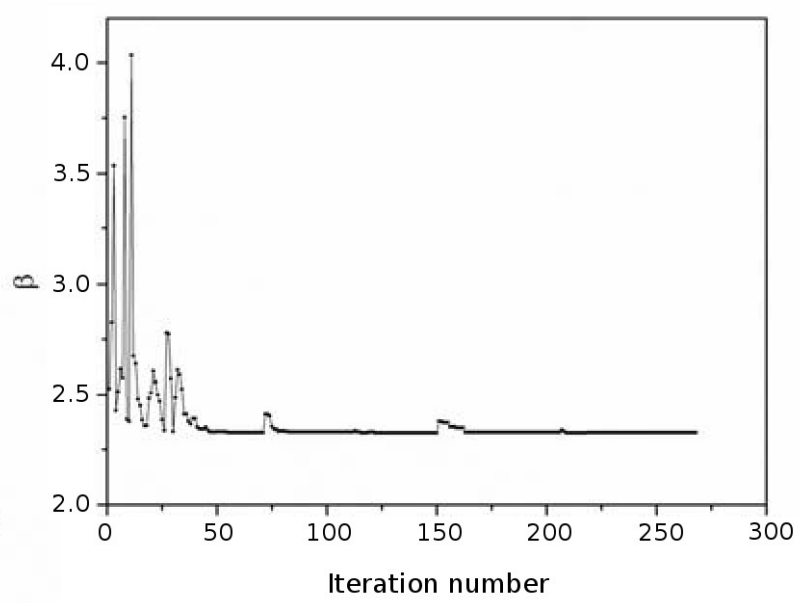

b)

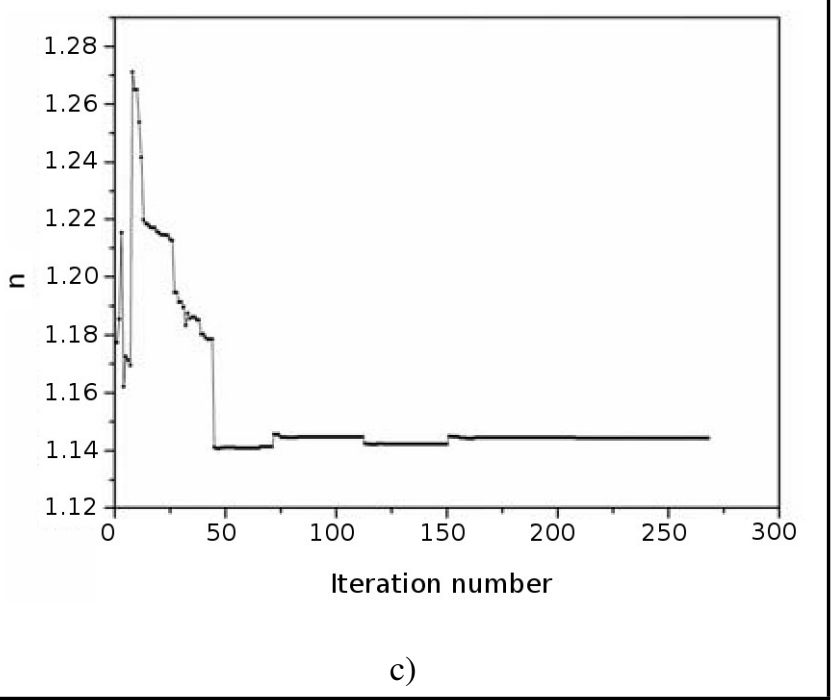

Figure 3. Iterative curves of reliability based optimization (the variation coefficient of random variables is 0.02 ): a) objective function, b) reliability index, and c) safety factor. 


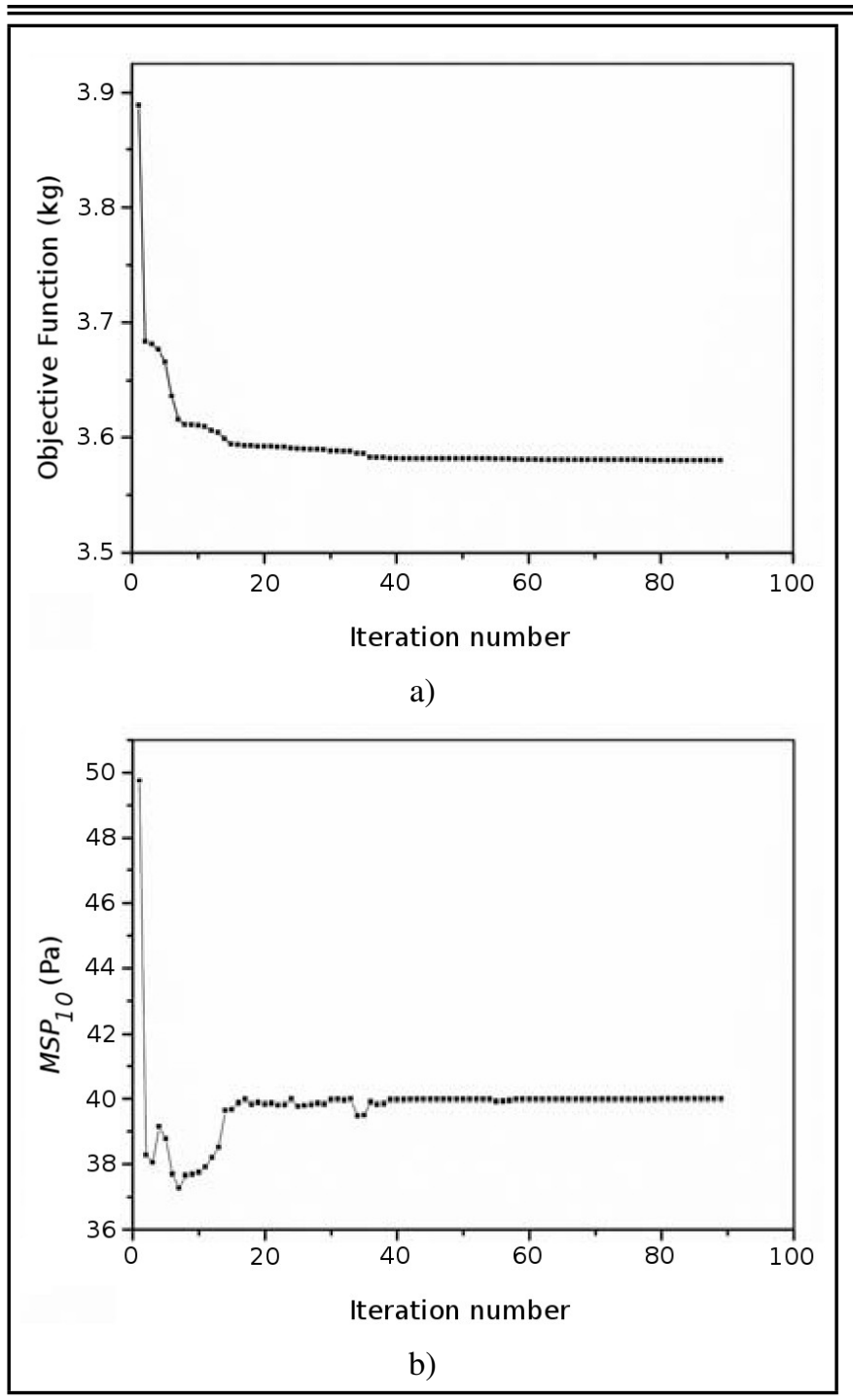

Figure 4. Iterative curves of the safety factor-based optimization ( $n=1.144)$ : a) objective function and b) MSP.

The iterative curves of the reliability-based optimization method are shown as Fig. 3 and the safety factor $n$ is obtained from reliability index $\beta$ according to Eq. (16).

\section{2) The safety factor-based optimization method}

In this example, the mean square sound pressure amplitude and the mean square sound pressure constraint value in stochastic reliability-based optimization corresponds to the stress $\mu_{s}$ and strength $\mu_{\delta}$ in the stress-strength interference theory, and $\sigma_{\delta}$ is 0 . According to Eq. (16), we can calculate the safety factor corresponding to the optimal solution $n=1.144$, which satisfies the requirement of reliability: $n$ is the mean safety factor obtained from the optimal solutions by stochastic reliability-based optimization (reliability is not less than 0.99). The mathematical model of the safety factor-based optimization method is

$$
\left\{\begin{array}{l}
\min W \\
\text { s.t. } M S P_{10} \leq 40 / n \\
3 \mathrm{~mm} \leq \mathbf{t}_{\mathbf{1}}, \mathbf{t}_{\mathbf{2}}, \mathbf{t}_{\mathbf{3}}, \mathbf{t}_{\mathbf{4}}, \mathbf{t}_{\mathbf{5}} \leq 7 \mathrm{~mm}
\end{array} .\right.
$$

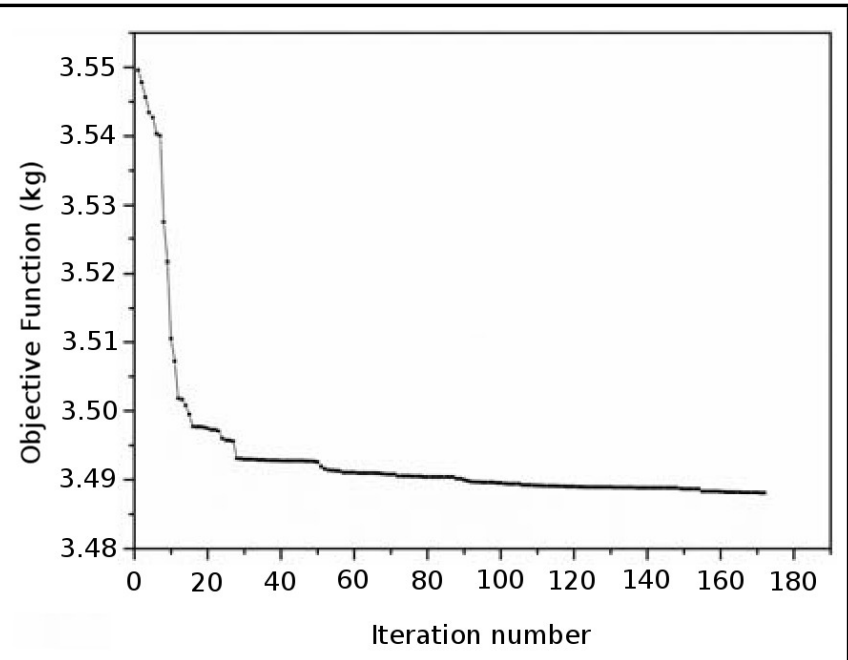

a)

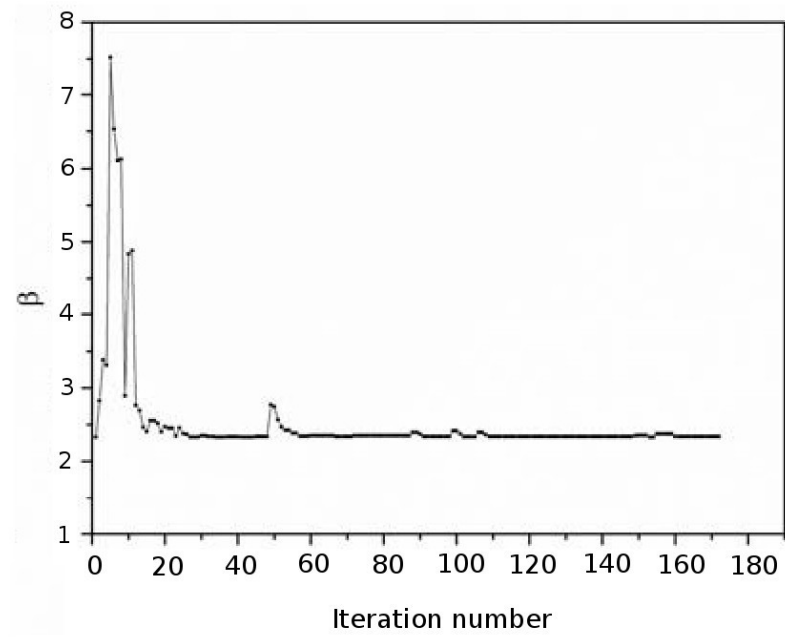

b)

Figure 5. Iterative curves of the reliability-based optimization with random parameters (The variation coefficient of random variables is 0.05 ): a) objective function and b) reliability index.

\subsection{Optimization When the Variation Coeffi- cient of Random Variables Is 0.05}

1) The stochastic reliability-based optimization method

\section{2) The safety factor-based optimization method}

According to Eq. (16), we can calculate the safety factor corresponding to the optimal solution and $n$ is 1.085 .

\section{OPTIMIZATION WHEN THE VARIATION COEFFICIENT OF RANDOM VARIABLES IS 0.1}

\section{1) The stochastic reliability-based optimization method}

\section{2) The safety factor-based optimization method}

According to Eq. (16), we can calculate the safety factor corresponding to the optimal solution and $n$ is 1.352 .

The results of the different optimization methods are shown in Table 1 to Table 3 . The objective function (structural 
Table 1. Comparison between the stochastic reliability-based optimization method and the safety factor-based method (the variation coefficient of random variables is 0.02).

\begin{tabular}{|c|c|c|c|c|c|c|c||}
\hline \multirow{2}{*}{$\begin{array}{c}\text { Optimization } \\
\text { type }\end{array}$} & \multicolumn{6}{|c|}{$\begin{array}{c}M S P_{10} \\
(\mathrm{~Pa})\end{array}$} & $\begin{array}{c}\text { Objective } \\
\text { function } \\
(\mathrm{Kg})\end{array}$ \\
\cline { 2 - 6 } & $t_{1}$ & $t_{2}$ & $t_{3}$ & $t_{4}$ & $t_{5}$ & & 3.8880 \\
\hline Initial values & 6.0000 & 6.0000 & 6.0000 & 6.0000 & 6.0000 & 49.7358 & 3.8282 \\
\hline $\begin{array}{c}\text { The deterministic } \\
\text { optimization method }\end{array}$ & 5.1848 & 5.6531 & 4.9841 & 3.0000 & 3.0004 & 39.9982 & 2.8250 \\
\hline $\begin{array}{c}\text { The stochastic } \\
\text { reliability-based } \\
\text { optimization method }\end{array}$ & 3.6495 & 6.3726 & 6.5625 & 5.4085 & 4.8695 & 34.9550 & 3.4814 \\
\hline $\begin{array}{c}\text { The safety } \\
\text { factor-based } \\
\text { method }\end{array}$ & 5.2485 & 5.2700 & 6.7173 & 6.4458 & 3.2036 & 39.9989 & 3.4843 \\
\hline
\end{tabular}

Table 2. Comparison between the stochastic reliability-based optimization method and the safety factor-based method (the variation coefficient of random variables is 0.05 ).

\begin{tabular}{|c|c|c|c|c|c|c|c|}
\hline \multirow[t]{2}{*}{$\begin{array}{l}\text { Optimization } \\
\text { type }\end{array}$} & \multicolumn{5}{|c|}{ Design variables $(\mathrm{mm})$} & \multirow[t]{2}{*}{$\begin{array}{c}M S P_{10} \\
(\mathrm{~Pa})\end{array}$} & \multirow{2}{*}{$\begin{array}{l}\text { Objective } \\
\text { function } \\
(\mathrm{Kg})\end{array}$} \\
\hline & $t_{1}$ & $t_{2}$ & $t_{3}$ & $t_{4}$ & $t_{5}$ & & \\
\hline Initial values & 6.0000 & 6.0000 & 6.0000 & 6.0000 & 6.0000 & 49.7358 & 3.8880 \\
\hline $\begin{array}{c}\text { The deterministic } \\
\text { optimization method }\end{array}$ & 5.1848 & 5.6531 & 4.9841 & 3.0000 & 3.0004 & 39.9982 & 2.8282 \\
\hline $\begin{array}{c}\text { The stochastic } \\
\text { reliability-based } \\
\text { optimization method }\end{array}$ & 6.9406 & 3.6815 & 5.8479 & 6.3075 & 4.1366 & 36.8664 & 3.4881 \\
\hline $\begin{array}{c}\text { The safety } \\
\text { factor-based } \\
\text { method }\end{array}$ & 5.5517 & 5.0535 & 6.8061 & 5.7098 & 3.5169 & 39.9996 & 3.4523 \\
\hline
\end{tabular}

Table 3. Comparison between the stochastic reliability-based optimization method and the safety factor-based method (the variation coefficient of random variables is 0.1 .

\begin{tabular}{|c|c|c|c|c|c|c|c||}
\hline \multirow{2}{*}{$\begin{array}{c}\text { Optimization } \\
\text { type }\end{array}$} & \multicolumn{6}{|c|}{ Design variables $(\mathrm{mm})$} & \multicolumn{2}{c|}{$\begin{array}{c}M S P_{10} \\
(\mathrm{~Pa})\end{array}$} & $\begin{array}{c}\text { Objective } \\
\text { function } \\
(\mathrm{Kg})\end{array}$ \\
\cline { 2 - 8 } & $t_{1}$ & $t_{2}$ & $t_{3}$ & $t_{4}$ & $t_{5}$ & & 3.8880 \\
\hline Initial values & 6.0000 & 6.0000 & 6.0000 & 6.0000 & 6.0000 & 49.7358 & 2.8282 \\
\hline $\begin{array}{c}\text { The deterministic } \\
\text { optimization method }\end{array}$ & 5.1848 & 5.6531 & 4.9841 & 3.0000 & 3.0004 & 39.9982 & 2.5768 \\
\hline $\begin{array}{c}\text { The stochastic } \\
\text { reliability-based } \\
\text { optimization method }\end{array}$ & 5.7675 & 5.0835 & 6.8865 & 6.5635 & 3.2975 & 29.5858 & 3.578 \\
\hline $\begin{array}{c}\text { The safety } \\
\text { factor-based } \\
\text { method }\end{array}$ & 6.7060 & 4.5992 & 6.6061 & 6.2562 & 3.3688 & 39.6467 & 3.5687 \\
\hline
\end{tabular}

weight) of the safety factor optimization method and stochastic reliability-based optimization method is greater than the deterministic optimization method because the latter does not consider the influence of the random parameters on the response andits constraint value is larger than the other two methods. In addition, as seen on Table 1, the optimal value of the deterministic optimization method of $t_{4}$ and $t_{5}$ is close to the lower limit of design variables $(3 \mathrm{~mm})$. If the uncertainties of the system parameter are considered, the design variables may be beyond the constraint scope $(3 \mathrm{~mm})$, which is why the reliability of the deterministic optimization method does not have strong robustness.

\section{CONCLUSIONS}

Compared with the deterministic optimization design method, the reliability-based method and the safety factor method based on reliability can consider the effect of structural parameter randomness on the structural performance, so the optimization results are more reasonable than that of the deterministic optimization method. In this paper, the safety factor is obtained from the reliability index (mean and stan- dard deviation) of the mean square acoustic pressure. Using this method to determine the safety factor and to implement the optimization design can help overcome the deficiency of the deterministic optimization method. Compared to the conventional design, the data processing and calculation process is simpler and the calculation precision is higher and closer to the actual. For example, when the variation coefficient of the random parameters is $0.02,0.05$, and 0.1 respectively, the difference of the two methods is about $1 \%$, which shows that the safety factor method can effectively consider the dispersion of parameters. The main advantage in using this method is that it can save materials and ensure reliability.

\section{ACKNOWLEDGEMENT}

This project is supported by the National Natural Science Foundation of China (Grant No.11002013; Grant No.11372025), Defense Industrial Technology Development Program (Grant No. A2120110001; Grant No. B2120110011) and the Aeronautical Science Foundation of China (Grant No. A2012ZA51010). 


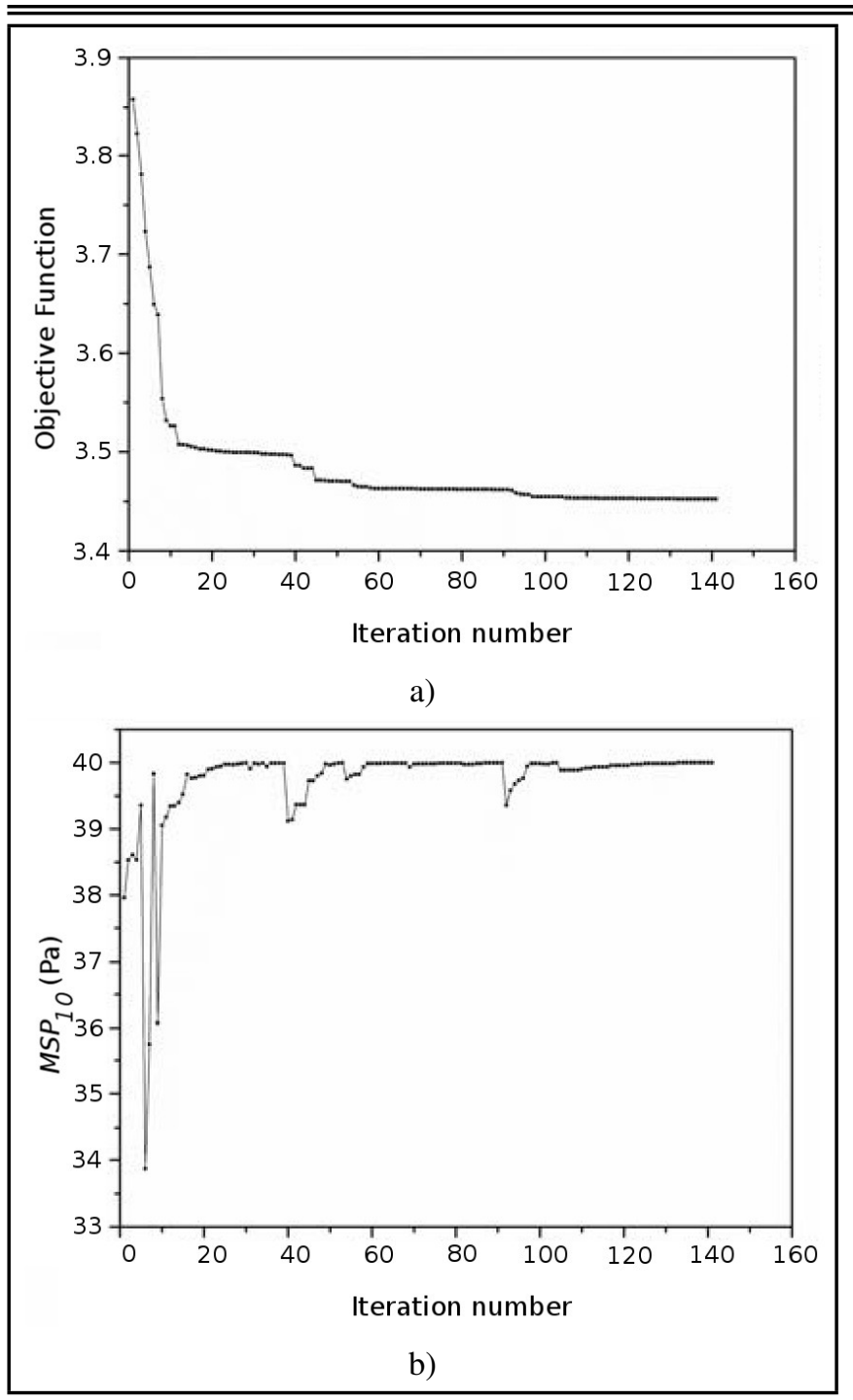

Figure 6. Iterative curves of the traditional safety factor-based optimization $(n=1.085)$ : a) objective function and b) MSP.

\section{REFERENCES}

1 Shuku, T. and Ishihara, K. The analysis of the Acoustic Field in Irregularly Shaped Rooms by the Finite Element Method, Journal of Sound and Vibration, 29 (1), 67-68, (1973). http://dx.doi.org/10.1016/s0022-460x(73)80126-9

2 Craggs, A. An Acoustic Finite Element Approach for Studying Boundary Flexibility and Sound Transmission between Irregular Enclosures, Journal of Sound and Vibration, 30 (3), 343-357, (1973). http://dx.doi.org/10.1016/s0022-460x(73)80243-3

3 Chen, L. and Schweikert, D. Sound Radiation from an Arbitrary Body, The Journal of the Acoustical society of America, 35 (10), 1626, (1963). http://dx.doi.org/10.1121/1.1918770

4 Chertock, G. Sound Radiation from Vibrating Surfaces, The Journal of the Acoustical Society of America, 36 (7), 13051313, (1964). http://dx.doi.org/10.1121/1.1919203

5 Marburg, S., Dienerowitz, F., Fritze, D., and Hardtke, H. J. Case Studies on Structural-acoustic Optimization of a Fi-

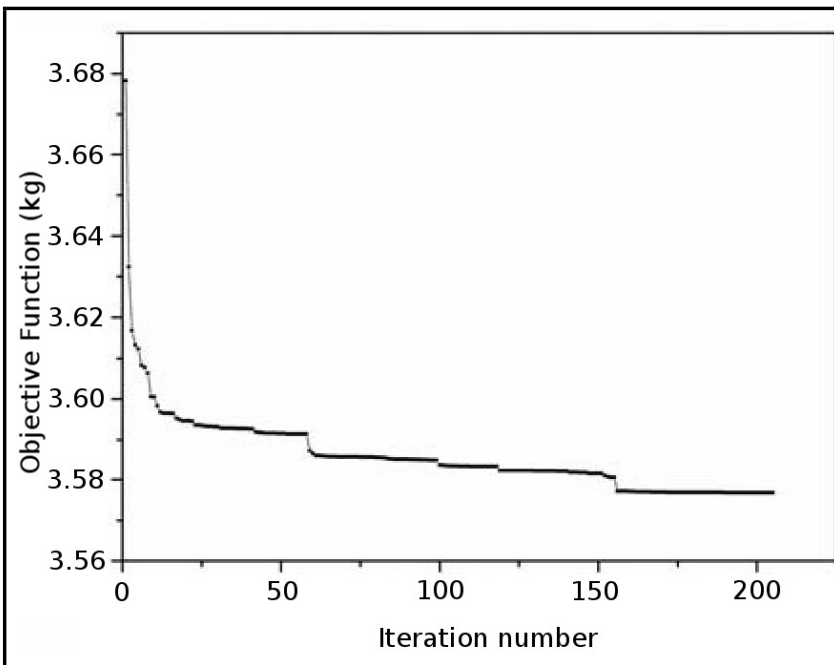

a)

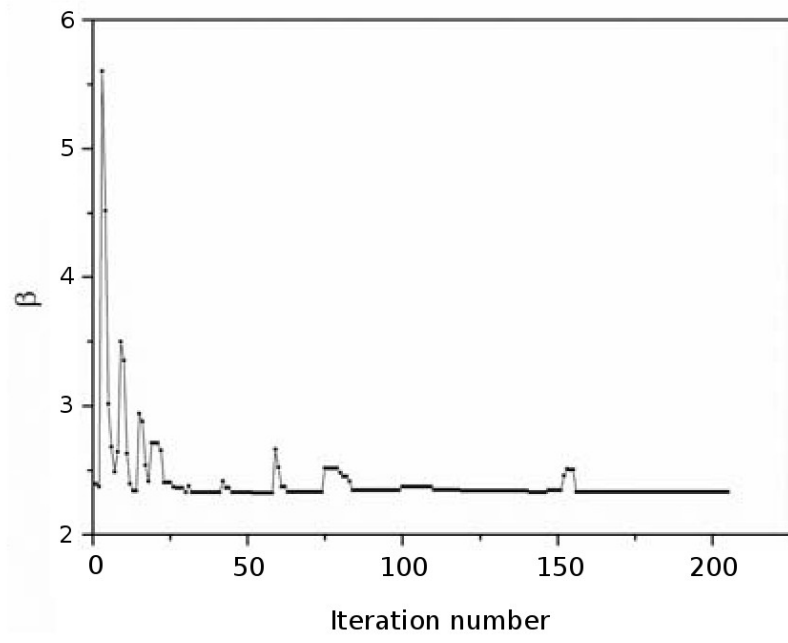

b)

Figure 7. Iterative curves of the reliability-based optimization with random parameters (The variation coefficient of random variables is 0.1 ): a) objective function and b) reliability index..

nite beam, Acta Acustica United with Acustica, 92 (3), 427439, (2006).

6 Bös, J. Numerical Optimization of the Thickness Distribution of Three-dimensional Structures with Respect to Their Structural Acoustic Properties, Structural and Multidisciplinary Optimization, 32 (1), 12-30, (2006). http://dx.doi.org/10.1007/s00158-005-0560-y

7 Mullen, R. and Muhanna, R. Bounds of Structural Response for All Possible Loading Combinations, Journal of Structural Engineering, 125 (1), 98-106, (1999). http://dx.doi.org/10.1061/(asce)0733-9445(1999)125:1(98)

8 Ma, Z. D. and Hagiwara, I. Sensitivity Analysis Methods for Coupled Acoustic-structural Systems Part I: Modal Sensitivities, AIAA Journal, 29 (11), 1787-1795, (1991). http://dx.doi.org/10.2514/3.61525

$9 \mathrm{Ma}$, Z. D. and Hagiwara, I. Sensitivity Analysis Methods for Coupled Acoustic-structural Systems Part ii: Direct Frequency Response and Its Sensitivities, AIAA Journal, 29 (11), 1796-1801, (1991). http://dx.doi.org/10.2514/3.61526 


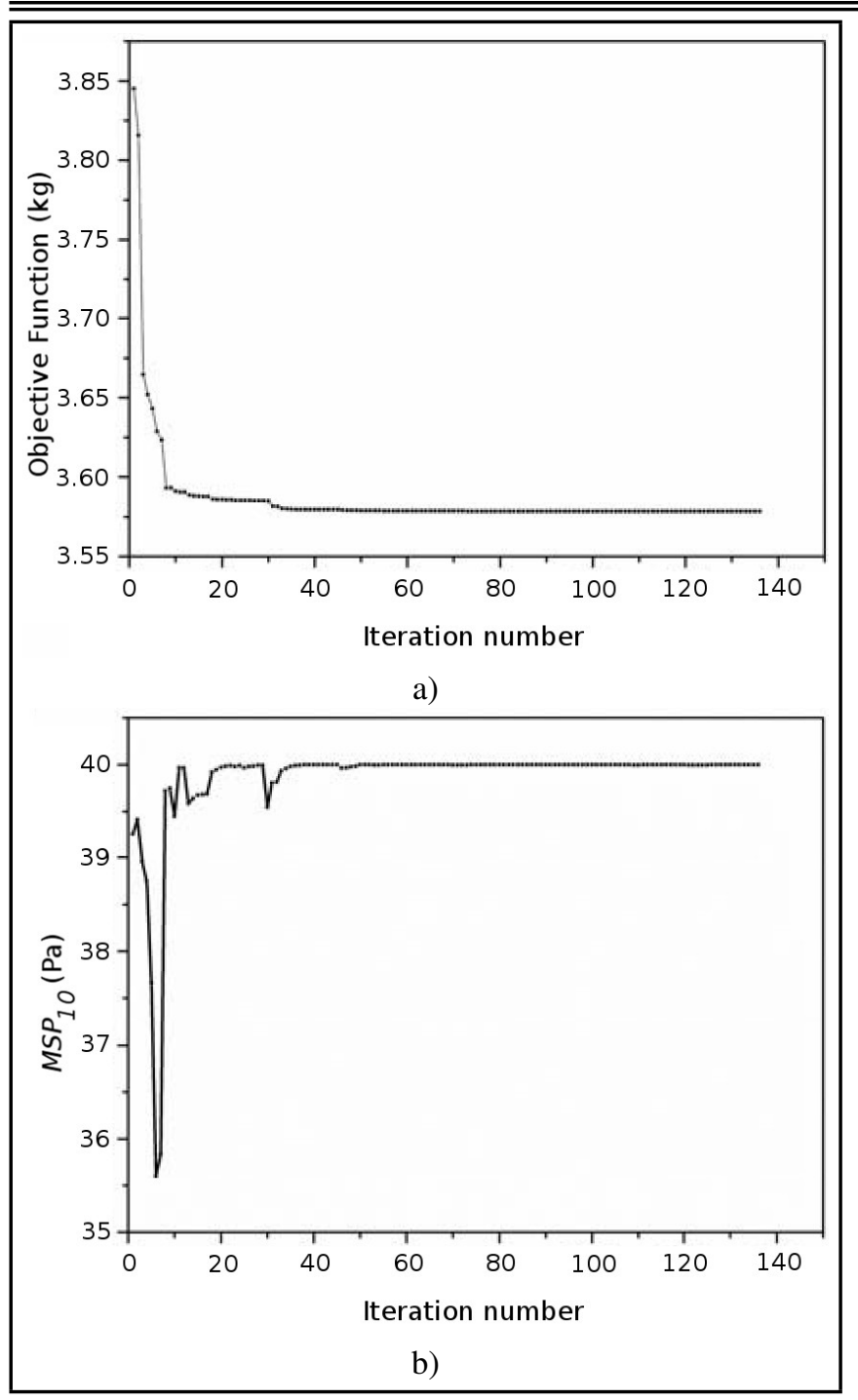

Figure 8. Iterative curves of the safety factor-based optimization $(n=1.352)$ : a) objective function and b) MSP.

10 Hagiwara, I. and Ma, Z. Sensitivity Calculation Method for Conducting Modal Frequency Response Analysis of Coupled Acoustic-structural Systems, JSME International Journal Series III, 35 (1), (1992). http://dx.doi.org/10.1299/jsmec1988.35.14

11 Hagiwara, I., Kozukue, W., and Ma, Z.D. The Development of Eigenmode Sensitivity Analysis Methods for Coupled Acoustic-structural Systems and Their Application to Reduction of Vehicle Interior Noise, Finite Elements in Analysis and Design, 14 (2), 235-248, (1993). http://dx.doi.org/10.1016/0168-874x(93)90023-j

12 Papadopoulos, C. I. Redistribution of the Low Frequency Acoustic Modes of a Room: A Finite Element-based Optimisation method, Applied Acoustics, 62 (11), 1267-1285, (2001). http://dx.doi.org/10.1016/s0003-682x(01)00002-0
13 Denli, H. and Sun, J. Optimization of Boundary Supports for Sound Radiation Reduction of Vibrating Structures, Journal of Vibration and Acoustics, 130 (1), (2008). http://dx.doi.org/10.1115/1.2776345

14 Christensen, S. T., Sorokin, S. V., and Olhoff, N. On Analysis and Optimization in Structural Acoustics - Part I: Problem Formulation and Solution Techniques, Structural Optimization, 16 (2-3), 83-95, (1998). http://dx.doi.org/10.1007/s001580050009

15 Christensen, S. T., Sorokin, S. V., and Olhoff, N. On Analysis and Optimization in Structural Acoustics - Part II: Exemplifications for Axisymmetric Structures, Structural Optimization, 16 (2-3), 96-107, (1998). http://dx.doi.org/10.1007/s001580050010

16 Elishakoff, I. and Ferracuti, B. Fuzzy Sets Based Interpretation of the Safety Factor, Fuzzy Sets and Systems, 157 (18), 2495-2512, (2006). http://dx.doi.org/10.1016/j.fss.2006.06.009

17 Wang, X., Qiu, Z., and Elishakoff, I. Non-probabilistic Set-theoretic Model for Structural Safety Measure, Acta Mechanica, 198 (1-2), 51-64, (2008). http://dx.doi.org/10.1007/s00707-007-0518-9

18 Elishakoff, I. and Starnes Jr, J. H. Safety factor and the non-deterministic approaches, Proc. of the 1999 AIAA/ASME/ASCE/AHS/ASC structrures, Structural Dynamics, and Materials Conference and Exhibit, (1999). http://dx.doi.org/10.2514/6.1999-1614

19 Ranjbar M., Hardtke H. J., Fritze D., et al. Finding the best design within limited time: a comparative case study on methods for optimization in structural acoustics. Journal of Computational Acoustics, 18 (2), 149-164, (2010). http://dx.doi.org/10.1142/s0218396x10004139

20 Ranjbar M., Marburg S., and Hardtke H. J. Structuralacoustic optimization of a rectangular plate: A tabu search approach, Finite Elements in Analysis and Design, 50, 142146, (2012). http://dx.doi.org/10.1016/j.finel.2011.09.005

21 Marburg S. and Hardtke H. J. A general concept for design modification of shell meshes in structuralacoustic optimizationPart II: Application to a floor panel in sedan interior noise problems. Finite Elements in Analysis and Design, 38 (8)737-754, (2002). http://dx.doi.org/10.1016/s0168-874x(01)00102-0

22 Fritze D., Marburg S., and Hardtke H. J. FEM-BEMcoupling and structural-acoustic sensitivity analysis for shell geometries, Computers \& structures, 143-154, 83 (2), (2005). http://dx.doi.org/10.1016/j.compstruc.2004.05.019 